\section{(2) OPEN ACCESS}

\title{
Upadacitinib for psoriatic arthritis refractory to biologics: SELECT-PSA 2
}

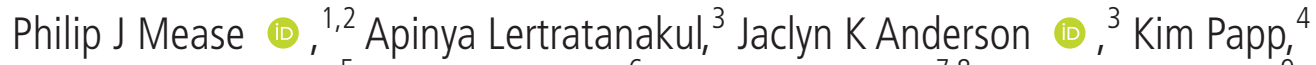 \\ Filip Van den Bosch, ${ }^{5}$ Shigeyoshi Tsuji, ${ }^{6}$ Eva Dokoupilova, ${ }^{7,8}$ Mauro Keiserman, ${ }^{9}$ \\ Xin Wang, ${ }^{3}$ Sheng Zhong, ${ }_{1}^{3}$ Reva M McCaskill, ${ }^{3}$ Patrick Zueger, ${ }^{3}$ Aileen L Pangan, ${ }^{3}$ \\ William Tillett ${ }^{10,11}$
}

\begin{abstract}
Handling editor Josef $S$
Smolen

Additional material is published online only. To view please visit the journal online (http://dx.doi.org/10.1136/ annrheumdis-2020-218870)
\end{abstract}

For numbered affiliations see

\section{Correspondence to}

Dr Philip J Mease,

Rheumatology, Swedish Medical Center, Seattle WA 98122, USA; pmease@philipmease.com

Received 13 August 2020 Revised 22 September 2020 Accepted 12 October 2020 Published Online First 3 December 2020 end of article.

\section{ABSTRACT}

Background Upadacitinib is a Janus kinase inhibitor under evaluation for the treatment of psoriatic arthritis (PsA). We evaluated upadacitinib in patients with PsA and prior inadequate response or intolerance to at least one biologic disease-modifying antirheumatic drug (DMARD).

Methods In this 24-week randomised, placebocontrolled, double-blind, phase 3 trial, 642 patients were randomised (2:2:1:1) to once per day upadacitinib 15 $\mathrm{mg}$ or $30 \mathrm{mg}$, placebo followed by upadacitinib $15 \mathrm{mg}$ or placebo followed by upadacitinib $30 \mathrm{mg}$ at week 24 . The primary endpoint was the proportion of patients achieving American College of Rheumatology (ACR) 20 response at week 12 . Achievement of minimal disease activity (MDA) was assessed at week 24 . Treatmentemergent adverse events are reported for all patients who received at least one dose of trial drug.

Results At week 12, significantly more patients receiving upadacitinib $15 \mathrm{mg}$ and $30 \mathrm{mg}$ versus placebo achieved ACR20 (56.9\% and $63.8 \%$ vs $24.1 \% ; p<0.001$ for both comparisons). At week 24, MDA was achieved by more upadacitinib $15 \mathrm{mg}$-treated $(25.1 \%)$ and 30 mg-treated patients $(28.9 \%)$ versus placebo $(2.8 \%$; $\mathrm{p}<0.001$ for both comparisons). Generally, the rates of treatment-emergent adverse events were similar with placebo and upadacitinib $15 \mathrm{mg}$ and higher with upadacitinib $30 \mathrm{mg}$ at week 24 . Rates of serious infections were $0.5 \%, 0.5 \%$ and $2.8 \%$ with placebo, upadacitinib $15 \mathrm{mg}$ and upadacitinib $30 \mathrm{mg}$, respectively. Conclusion In this trial of patients with active PsA who had inadequate response or intolerance to at least one biologic DMARD, upadacitinib $15 \mathrm{mg}$ and $30 \mathrm{mg}$ was more effective than placebo over 24 weeks in improving signs and symptoms of PsA.

Clinical trial registration number NCT03104374

\section{INTRODUCTION}

Check for updates

(c) Author(s) (or their employer(s)) 2021. Re-use permitted under CC BY-NC. No commercial re-use. See rights and permissions. Published by BMJ.

To cite: Mease PJ Lertratanakul A, Anderson JK et al. Ann Rheum Dis 2021:80:312-320
Psoriatic arthritis (PsA) is a systemic inflammatory disease with heterogeneous clinical manifestations such as plaque psoriasis, arthritis, dactylitis and enthesitis. Current treatment guidelines for PsA vary, recommending conventional synthetic disease-modifying antirheumatic drugs (DMARDs) such as methotrexate as initial therapy, followed by biologic DMARDs (tumour necrosis factor inhibitors (TNFi), interleukin-12/23 or interleukin-17 inhibitors) or targeted synthetic DMARDs, such as apremilast or tofacitinib, or TNFi initially, followed

\section{Key messages}

What is already known about this subject?

- Despite the availability of biologic diseasemodifying antirheumatic drugs (DMARDs) in psoriatic arthritis, only a small proportion of patients achieve the recommended target of minimal disease activity; therefore, additional treatment options are needed.

What does this study add?

- In this phase 3 trial of patients with psoriatic arthritis refractory or intolerant to biologic DMARDs, greater efficacy was demonstrated for once per day upadacitinib $15 \mathrm{mg}$ and 30 mg versus placebo for clinical manifestations of psoriatic arthritis including musculoskeletal symptoms (peripheral arthritis, enthesitis, dactylitis and spondylitis), psoriasis, physical function, pain, fatigue and quality of life.

How might this impact on clinical practice or future developments?

- Once per day upadacitinib $15 \mathrm{mg}$ and $30 \mathrm{mg}$ demonstrated significant efficacy in patients with psoriatic arthritis refractory or intolerant to prior biologic DMARD therapy in the 24-week placebo-controlled period of this study.

- Efficacy was observed as early as week 2. Efficacy was demonstrated in all measures of the various core clinical domains of psoriatic arthritis. More upadacitinib-treated patients achieved a state of minimal disease activity.

- The safety findings are consistent with the known safety profile of upadacitinib observed in rheumatoid arthritis; no new safety risks have been identified.

by other approved therapies. ${ }^{1-3}$ While multiple therapeutic choices are now available, additional options are needed as under one-third achieving minimal disease activity (MDA) in most placebocontrolled trials. $^{4-9}$

Upadacitinib is an oral, reversible Janus kinase inhibitor (JAKi) with selectivity for JAK1 over JAK2, JAK3 and tyrosine kinase $2,{ }^{10}$ approved for the treatment of rheumatoid arthritis based on five phase 3 studies. ${ }^{11-15}$ Improvements in multiple composite measures, including stringent measures 
of low disease activity and remission, as well as patient-reported outcomes such as morning stiffness and pain, after treatment with upadacitinib $15 \mathrm{mg}$ once per day, in patients with rheumatoid arthritis who failed biologic DMARDs were similar to those in patients who had failed conventional synthetic DMARDs or methotrexate. ${ }^{11-15}$ We report the results of the SELECT-PsA 2 trial, a randomised phase 3 trial of upadacitinib in patients with active PsA who have had an inadequate response or intolerance to at least one biologic DMARD.

\section{PATIENTS AND METHODS \\ Patients}

Eligible patients were 18 years of age or older with active PsA, had a diagnosis of PsA with symptom onset for $\geq 6$ months, fulfilled the Classification Criteria for Psoriatic Arthritis (CASPAR), ${ }^{16}$ had historical or current plaque psoriasis, $\geq 3$ swollen joints (of 66 ) and $\geq 3$ tender joints (of 68) at screening and at baseline, and an inadequate response or intolerance to at least one biologic DMARD. Patients were excluded if they had previous exposure to a JAKi, had a history of fibromyalgia, had arthritis with onset prior to age 17 years or had diagnosis of inflammatory joint disease other than PsA. Online supplemental section 2 provides a complete list of eligibility criteria.

\section{Trial design}

A multicentre, randomised, double-blind, phase 3 placebocontrolled trial at 123 sites in 17 countries has been ongoing since April 2017, conducted per the International Conference on Harmonization guidelines, applicable regulations and guidelines governing clinical trial conduct, and the Declaration of Helsinki. All patients provided written informed consent.

\section{Randomisation and treatments}

An Interactive Response Technology system was used to assign patients, in a $2: 2: 1: 1$ ratio, to one of the following regimens: upadacitinib $15 \mathrm{mg}$ once per day, upadacitinib $30 \mathrm{mg}$ once per day or placebo switched to either upadacitinib $15 \mathrm{mg}$ or $30 \mathrm{mg}$ once per day at week 24. Stable background treatment of nonsteroidal anti-inflammatory drugs, corticosteroids (equivalent to $\leq 10 \mathrm{mg}$ /day prednisone) and $\leq 2$ non-biologic DMARDs were permitted; background therapy was not required. Concomitant biologic therapies were prohibited. Concomitant treatments specifically for psoriasis (eg, topicals, light therapy, retinoids) were not permitted until after week 16 .

Starting at week 16, patients who did not achieve $\geq 20 \%$ improvement in tender and swollen joint counts compared with baseline at weeks 12 and 16 had background medication(s) adjusted or initiated. Starting at week 36, patients who did not achieve $\geq 20 \%$ improvement in tender and swollen joint counts compared with baseline at two consecutive visits were discontinued from the study. All patients who completed week 56 were eligible to remain in the extension period of the trial for up to 3 years of trial participation in total (online supplemental figure 1).

Randomisation was stratified by extent of psoriasis $(\geq 3 \% /<3 \%$ body surface area (BSA)), current use of at least 1 DMARD and number of prior biologic DMARDs failed (1 versus $>1$ ). The trial is ongoing; data presented include the 24-week placebocontrolled period during which investigators and the sponsor were blinded to treatment assignment.

\section{Assessments}

The primary endpoint was the proportion of patients achieving American College of Rheumatology (ACR) 20 response at week
12. Multiplicity-controlled secondary endpoints for each dose of upadacitinib versus placebo included: at week 12, change from baseline in Health Assessment Questionnaire-Disability Index (HAQ-DI) ${ }^{17}$; Functional Assessment of Chronic Illness Therapy-Fatigue (FACIT-F) score $^{18}$ and Short Form Health Survey questionnaire (SF-36) Physical Component Summary (PCS) score $^{19}$; at week 16 , proportion of patients achieving a Static Investigator Global Assessment (sIGA) of Psoriasis of 0 or 1 and at least a 2 point improvement from baseline (sIGA 0/1) for patients with baseline sIGA $\geq 2^{20}$; Psoriasis Area Severity Index (PASI) 75 response for patients with $\geq 3 \%$ BSA-psoriasis at baseline ${ }^{21}$; and change from baseline in Self-Assessment of Psoriasis Symptoms (SAPS) Questionnaire ${ }^{22}$; and at week 24 , proportion of patients achieving MDA. ${ }^{23}$ Additional key secondary efficacy endpoints included ACR50/70 response at week 12 and ACR20 response at week 2. Exploratory endpoints were proportion of patients achieving PASI90/100 response, resolution of enthesitis (defined by Leeds Enthesitis Index $($ LEI $)=0)$ for patients with baseline LEI $>0^{24}$ and Spondyloarthritis Research Consortium of Canada Enthesitis Index $(($ SPARCC $)=0)$ for patients with baseline SPARCC Enthesitis Index $>0^{25}$ and resolution of dactylitis (defined by Leeds Dactylitis Index $(\mathrm{LDI})=0$ ) for patients with baseline $\mathrm{LDI}>0,{ }^{26}$ and change from baseline in individual components of ACR response, Disease Activity in Psoriatic Arthritis (DAPSA) score ${ }^{27}$ and morning stiffness (mean of Bath Ankylosing Spondylitis Disease Activity Index (BASDAI) questions 5 and 6). All outcomes are defined in online supplemental table $\mathrm{S} 1$.

Adverse events (AEs) and clinical laboratory testing are reported through week 24 . An independent, external Cardiovascular Adjudication Committee blindly adjudicated deaths and cardiovascular events per predefined event definitions. An internal Gastrointestinal (GI) Perforation Adjudication Committee blindly adjudicated reported GI perforation events as stated in the GI perforation charter.

\section{Statistical analysis}

Efficacy analyses were conducted on all randomised patients who had received at least one dose of trial drug. A sample size of 630 patients was planned to provide at least $90 \%$ power for a 20\% difference in ACR20 response rate (assuming a placebo ACR20 response rate of 20\%) and for most of the key secondary endpoints (online supplemental section 3).

The overall type I error rate of primary and ranked key secondary endpoints was strongly controlled using a graphical multiple testing procedure starting with the primary endpoint using $\alpha / 2$ for each dose followed by a prespecified $\alpha$ transfer path, which included downstream transfer along the endpoint sequence within each dose as well as cross-dose transfer (online supplemental figure S2). Once an endpoint was claimed significant, its significance level was transferred to subsequent endpoint(s) following the prespecified order and weight. All other outcomes were prespecified in the protocol and statistical analysis plan without adjustment for multiplicity.

The Cochran-Mantel-Haenszel test adjusting for the stratification factor of current DMARD use (yes/no) was used to compare treatment binary endpoints. Non-responder imputation was used for missing data handling, where patients with missing data at the specified week or those who prematurely discontinued the trial drug were considered non-responders. For continuous endpoints, analyses were conducted using the mixed-effects model repeated measures analysis based on observed longitudinal data, which included the fixed effects of treatment, visit, 
treatment-by-visit interaction, the stratification factor of current DMARD use (yes/no) and the continuous fixed covariate of baseline measurement. An unstructured variance covariance matrix was used. Patients who met the discontinuation criteria were considered non-responders.
RESULTS

\section{Patients}

Of the 642 patients randomised, 641 received at least one dose of trial drug (placebo, $\mathrm{n}=212$; upadacitinib $15 \mathrm{mg}, \mathrm{n}=211$; upadacitinib $30 \mathrm{mg}, \mathrm{n}=218$; online supplemental figure S3). Overall,

\begin{tabular}{|c|c|c|c|}
\hline & $\begin{array}{l}\text { Placebo } \\
\mathrm{N}=212\end{array}$ & $\begin{array}{l}\text { Upadacitinib } 15 \mathrm{mg} \text { QD } \\
\mathrm{N}=211\end{array}$ & $\begin{array}{l}\text { Upadacitinib } 30 \mathrm{mg} \text { QD } \\
\mathrm{N}=218\end{array}$ \\
\hline Female, $n(\%)$ & $120(56.6)$ & $113(53.6)$ & $115(52.8)$ \\
\hline Age (years) & $54.1 \pm 11.5$ & $53.0 \pm 12.0$ & $53.0 \pm 11.9$ \\
\hline \multicolumn{4}{|l|}{ Race, n (\%) } \\
\hline White & $186(87.7)$ & $183(86.7)$ & $196(89.9)$ \\
\hline Black or African American & $7(3.3)$ & $5(2.4)$ & $5(2.3)$ \\
\hline American Indian/Alaska Native & 0 & $3(1.4)$ & 0 \\
\hline Native Hawaiian or other Pacific Islander & $1(0.5)$ & $1(0.5)$ & $1(0.5)$ \\
\hline Asian & $17(8.0)$ & $19(9.0)$ & $16(7.3)$ \\
\hline Multiple & $1(0.5)$ & 0 & 0 \\
\hline Duration of PsA symptoms (years) & $14.6 \pm 11.7$ & $12.2 \pm 8.8$ & $13.3 \pm 10.8$ \\
\hline Duration since PsA diagnosis (years) & $11.0 \pm 10.3$ & $9.6 \pm 8.4$ & $9.7 \pm 8.7$ \\
\hline \multicolumn{4}{|l|}{ Number of prior failed biologic DMARDs, $\mathrm{n}(\%)$} \\
\hline $0^{*}$ & $18(8.5)$ & $16(7.6)$ & $17(7.8)$ \\
\hline 1 & $135(63.7)$ & $126(59.7)$ & $130(59.6)$ \\
\hline 2 & $35(16.5)$ & $35(16.6)$ & $46(21.1)$ \\
\hline$\geq 3$ & $24(11.3)$ & $34(16.1)$ & $25(11.5)$ \\
\hline Monotherapy, n (\%) & $112(52.8)$ & $113(53.6)$ & $120(55.0)$ \\
\hline \multicolumn{4}{|l|}{ Any non-biologic DMARD at baseline, $\mathrm{n}(\%)$} \\
\hline MTX alone & $75(35.4)$ & $74(35.1)$ & $73(33.5)$ \\
\hline MTX+another non-biologic DMARD & $7(3.3)$ & $6(2.8)$ & $5(2.3)$ \\
\hline Non-biologic DMARD other than MTX & $18(8.5)$ & $18(8.5)$ & $20(9.2)$ \\
\hline \multicolumn{4}{|c|}{ MTX dose for patients with concomitant MTX alone at baseline (mg/week) } \\
\hline Mean & 16.26 & 15.06 & 16.76 \\
\hline Median & 17.5 & 15.0 & 17.5 \\
\hline Steroid use at baseline, $\mathrm{n}(\%)$ & $24(11.3)$ & $22(10.4)$ & $13(6.0)$ \\
\hline NSAID use at baseline, $\mathrm{n}(\%)$ & $125(59.0)$ & $124(58.8)$ & $129(59.2)$ \\
\hline RF status positive, $\mathrm{n}(\%)$ & $6(2.8)$ & $11(5.2)$ & $8(3.7)$ \\
\hline Anti-CCP status positive, $n(\%)$ & $10(4.7)$ & $7(3.3)$ & $5(2.3)$ \\
\hline TJC68 & $25.3 \pm 17.6$ & $24.9 \pm 17.3$ & $24.2 \pm 15.9$ \\
\hline SJC66 & $12.0 \pm 8.9$ & $11.3 \pm 8.2$ & $12.9 \pm 9.4$ \\
\hline hs-CRP > ULN† (mg/L), n (\%) & $121(57.1)$ & $126(59.7)$ & $128(58.7)$ \\
\hline hs-CRP (mg/L) & $10.4 \pm 18.5$ & $11.2 \pm 18.5$ & $10.5 \pm 17.2$ \\
\hline HAQ-DI & $1.23 \pm 0.7$ & $1.10 \pm 0.6$ & $1.19 \pm 0.7$ \\
\hline Patient's assessment of pain (NRS 0-10) & $6.6 \pm 2.1$ & $6.4 \pm 2.1$ & $6.2 \pm 2.2$ \\
\hline BSA-psoriasis $\geq 3 \%, n(\%)$ & $131(61.8)$ & $130(61.6)$ & $131(60.1)$ \\
\hline PASI (for baseline BSA-Ps $\geq 3 \%$ ) & $11.7 \pm 11.4$ & $10.1 \pm 9.2$ & $8.9 \pm 9.1$ \\
\hline BSA-psoriasis $>0 \%, n(\%)$ & $198(93.4)$ & $202(95.7)$ & $202(92.7)$ \\
\hline BSA-psoriasis (for baseline $>0 \%$ ) & $12.8 \pm 18.4$ & $10.0 \pm 15.7$ & $10.0 \pm 15.8$ \\
\hline \multicolumn{4}{|l|}{ sIGA of psoriasis score, $n(\%)$} \\
\hline 0 & $17(8.0)$ & $9(4.3)$ & $16(7.3)$ \\
\hline 1 & $32(15.1)$ & $31(14.7)$ & $38(17.4)$ \\
\hline 2 & $59(27.8)$ & $82(38.9)$ & $78(35.8)$ \\
\hline 3 & $88(41.5)$ & $78(37.0)$ & $77(35.3)$ \\
\hline 4 & $16(7.5)$ & $11(5.2)$ & $9(4.1)$ \\
\hline \multicolumn{4}{|l|}{ Presence of enthesitis } \\
\hline LEI $>0, n(\%)$ & $144(67.9)$ & $133(63.0)$ & $152(69.7)$ \\
\hline SPARCC Enthesitis Index >0, n (\%) & $173(81.6)$ & $172(81.5)$ & $179(82.1)$ \\
\hline Presence of dactylitis (defined as LDI >0), $n(\%)$ & $64(30.2)$ & $55(26.1)$ & $50(22.9)$ \\
\hline Morning stiffness scoreł & $5.8 \pm 2.5$ & $6.0 \pm 2.5$ & $5.7 \pm 2.7$ \\
\hline \multicolumn{4}{|c|}{$\begin{array}{l}\text { Values are mean } \pm \text { SD unless noted. } \\
\text { *Patients with intolerance but not inadequate response to a biologic DMARD. } \\
\text { tULN=2.87 mg/L. } \\
\text { ¥Morning stiffness score is the mean of BASDAI questions } 5 \text { and } 6 . \\
\text { Anti-CCP, anti-cyclic citrullinated peptide; ASDAS, Ankylosing Spondylitis Disease Activity Score; BASDAI, Bath Ankylosing Spondylitis Disease Activity Index; BSA, body surface area; DMARD, disease-modifying antirheumatic drug; HAQ-DI, Health } \\
\text { Assessment Questionnaire-Disability Index; hs-CRP, high-sensitivity C-reactive protein; LDI, Leeds Dactylitis Index; LEI, Leeds Enthesitis Index; MTX, methotrexate; NRS, Numeric Rating Scale; NSAID, non-steroidal anti-inflammatory drug; PASI, } \\
\text { Psoriasis Area Severity Index; Ps, psoriasis; PsA, psoriatic arthritis; QD, once per day; RF, rheumatoid factor; SIGA, Static Investigator Global Assessment; SJC, swollen joint count; SPARCC, Spondyloarthritis Research Consortium of Canada; TJC, } \\
\text { tender joint count; ULN, upper limit normal. }\end{array}$} \\
\hline
\end{tabular}


A.

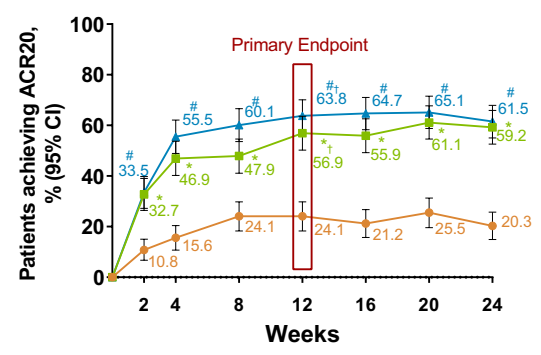

B.

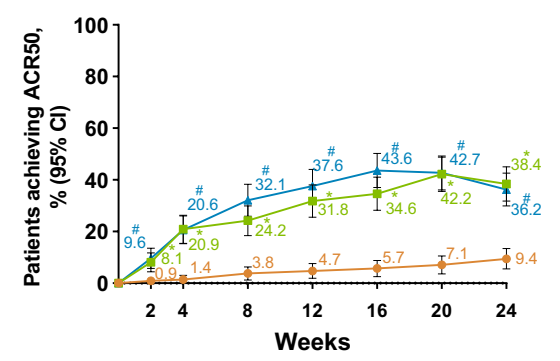

C.

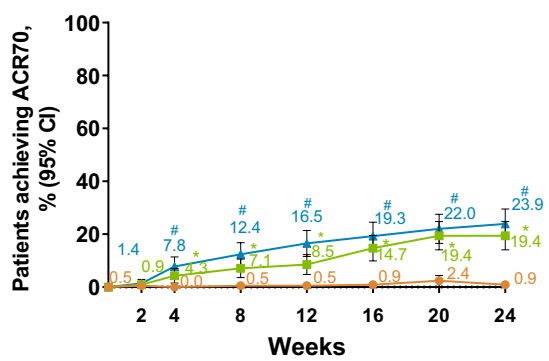

- Placebo $\rightarrow$ Upadacitinib 15mg QD $\rightarrow$ Upadacitinib 30mg QD

Figure 1 Proportions of patients achieving (A) ACR20 (B) ACR50 and (C) ACR70 response over 24 weeks (NRI). * $p \leq 0.05$ for comparison of upadacitinib $15 \mathrm{mg}$ once per day versus placebo; $\# \mathrm{p} \leq 0.05$ for comparison of upadacitinib $30 \mathrm{mg}$ once per day versus placebo; †Significant in the multiplicity-controlled analysis. ACR20/50/70, 20\%/50\%/70\% improvement in American College of Rheumatology criteria. Results are based on nonresponder imputation. $95 \% \mathrm{Cls}$ for response rate were calculated based on normal approximation to the binominal distribution. $95 \%$ Cls for response rate difference were calculated based on normal approximation. Nominal $p$ value was constructed using Cochran-Mantel-Haenszel test adjusted for the main stratification factor of current disease-modifying antirheumatic drug use (yes/no).

$543(84.6 \%)$ patients completed week 24 on trial drug. Baseline demographics, disease characteristics and disease severity were generally balanced across treatment arms (table 1).

\section{Efficacy}

At week 12, significantly more patients achieved an ACR20 response in the upadacitinib $15 \mathrm{mg}$ and $30 \mathrm{mg}$ arms versus the placebo arm $(56.9 \%, 63.8 \%$ and $24.1 \%$, respectively; $\mathrm{p}<0.001$ for both upadacitinib arms vs placebo; figure 1, tables 2 and 3 ). By week 2, ACR20 response was achieved by more upadacitinib $15 \mathrm{mg}$-treated and $30 \mathrm{mg}$-treated patients (nominal $\mathrm{p}<0.001$ ). The proportion of patients with ACR20 response continued to increase over time in both treatment groups with the plateau of response observed at week 12 for the upadacitinib $30 \mathrm{mg}$ group, whereas the proportion of patients with ACR20 response in the upadacitinib $15 \mathrm{mg}$ group increased through week 20, approximating the response rate in the $30 \mathrm{mg}$ dose group by the end of the placebo-controlled period. Subgroup analyses for ACR20 based on demographic and baseline disease characteristics are shown in online supplemental figure S4. Response rates for upadacitinib $15 \mathrm{mg}$ and upadacitinib $30 \mathrm{mg}$ were $44.9 \%$ and $64.8 \%$ in the subgroup of patients who had failed $>1$ biologic DMARD and $55.8 \%$ and $66.7 \%$ in the subgroup of patients that were on monotherapy; these responses were similar to results in the overall population. Additionally, improvements in ACR50 and ACR70 were observed with both upadacitinib doses versus placebo at week 12 (figure 1 and table 3). From week 2 through week 24, improvement from baseline in all components of ACR response was observed with upadacitinib $15 \mathrm{mg}$ or $30 \mathrm{mg}$ versus placebo (online supplemental figure S5).

The $15 \mathrm{mg}$ and $30 \mathrm{mg}$ doses of upadacitinib showed greater improvement versus placebo with respect to all key secondary endpoints (table 2 and online supplementary material).

By week 12 and through week 24, improvement in psoriasis was observed with both upadacitinib doses versus placebo as measured by PASI75/90/100 (at week 16, $\mathrm{p}<0.001$ for PASI75 and nominal $\mathrm{p}<0.001$ for PASI90/100; nominal $\mathrm{p}<0.001$ for all the other time points; figure 2$)$ and sIGA $0 / 1(\mathrm{p}<0.001$ at week 16 ; nominal $p<0.001$ for weeks 12 and 24 ; online supplemental figure S6). The changes from baseline in SAPS were greater for both upadacitinib arms versus placebo at weeks $16(\mathrm{p}<0.001)$ and 24 (nominal $\mathrm{p}<0.001$; online supplemental figure S7).

Improvements in physical function were observed in patients on both doses of upadacitinib versus placebo based on the mean change from baseline in HAQ-DI from week 2 through week 24 $(\mathrm{p}<0.001$ at week 12$)$ and SF-36 PCS at weeks $12(\mathrm{p}<0.001)$ and 24 (nominal $\mathrm{p}<0.001$; online supplemental figure $\mathrm{S} 8$ ). Patients on both doses of upadacitinib reported improvements in fatigue as assessed by FACIT-F versus placebo at weeks 12 $(\mathrm{p}<0.001)$ and 24 (nominal $\mathrm{p}<0.001$; online supplemental figure S9). Mean improvements from baseline in morning stiffness were observed at weeks 12 and 24 (nominal $\mathrm{p}<0.001$; online supplemental figure S10).

Resolution of enthesitis using both the LEI and the SPARCC enthesitis index and of dactylitis was reported in a higher proportion of patients on either dose of upadacitinib versus placebo from week 12 to week 24 (nominal $\mathrm{p}<0.001$; table 3 and online supplemental figure S11).

A higher proportion of patients receiving either dose of upadacitinib achieved MDA through week 24 versus placebo $(\mathrm{p}<0.001$ at week 24; nominal $\mathrm{p}<0.001$ for weeks 12 and 16; figure 3).

Mean changes from baseline in the DAPSA score were greater with both upadacitinib doses versus placebo through week 24 (nominal $\mathrm{p}<0.001$ for all time points; figure 4).

\section{Safety}

Through week 24, the rate of overall treatment-emergent AEs (TEAEs) was higher in the upadacitinib $30 \mathrm{mg}$ arm and rates of serious AEs (SAEs) and TEAEs leading to discontinuation of trial drug were higher with both upadacitinib doses versus placebo (table 4).

The most commonly reported TEAEs were upper respiratory tract infection and nasopharyngitis in upadacitinib-treated patients (online supplemental table S3). SAEs were reported in 4 (1.9\%) patients on placebo, $12(5.7 \%)$ on upadacitinib $15 \mathrm{mg}$ and $18(8.3 \%)$ on upadacitinib $30 \mathrm{mg}$. Serious infections occurred in one patient each $(0.5 \%)$ on placebo and upadacitinib $15 \mathrm{mg}$ and six $(2.8 \%)$ patients on upadacitinib $30 \mathrm{mg}$. Pneumonia was the most frequently reported serious infection (one patient on 
Table 2 Primary and multiplicity-controlled efficacy endpoints

\begin{tabular}{|c|c|c|c|}
\hline & Placebo & $\begin{array}{l}\text { Upadacitinib } 15 \\
\text { mg QD }\end{array}$ & $\begin{array}{l}\text { Upadacitinib } 30 \\
\text { mg QD }\end{array}$ \\
\hline \multicolumn{4}{|l|}{ ACR20 response at week 12} \\
\hline $\mathrm{N}$ & 212 & 211 & 218 \\
\hline$n(\%)$ & $51(24.1)$ & $120(56.9)$ & $139(63.8)$ \\
\hline $\begin{array}{l}\text { Response rate mean difference vs placebo } \\
(95 \% \mathrm{Cl})\end{array}$ & & $\begin{array}{l}32.8(24.0 \text { to } \\
41.6)\end{array}$ & $\begin{array}{l}39.7(31.1 \text { to } \\
48.3)\end{array}$ \\
\hline$P$ value & & $<0.001$ & $<0.001$ \\
\hline \multicolumn{4}{|l|}{ HAQ-DI change from baseline at week 12} \\
\hline $\mathrm{N}$ & 180 & 199 & 204 \\
\hline LS mean $(95 \% \mathrm{Cl})$ & $\begin{array}{l}-0.10(-0.16 \text { to } \\
-0.03)\end{array}$ & $\begin{array}{l}-0.30(-0.37 \text { to } \\
-0.24)\end{array}$ & $\begin{array}{l}-0.41(-0.47 \text { to } \\
-0.35)\end{array}$ \\
\hline LS mean difference $(95 \% \mathrm{Cl})$ & & $\begin{array}{l}-0.21(-0.30 \text { to } \\
-0.12)\end{array}$ & $\begin{array}{l}-0.31(-0.40 \text { to } \\
-0.22)\end{array}$ \\
\hline$P$ value & & $<0.001$ & $<0.001$ \\
\hline \multicolumn{4}{|l|}{$\begin{array}{l}\text { FACIT-F score change from baseline at } \\
\text { week } 12\end{array}$} \\
\hline $\mathrm{N}$ & 184 & 201 & 206 \\
\hline LS mean $(95 \% \mathrm{Cl})$ & $1.3(0.1$ to 2.5$)$ & $5.0(3.8$ to 6.1$)$ & 6.1 (4.9 to 7.2$)$ \\
\hline LS mean difference $(95 \% \mathrm{Cl})$ & & $3.7(2.0$ to 5.4$)$ & 4.8 (3.1 to 6.4$)$ \\
\hline$P$ value & & $<0.001$ & $<0.001$ \\
\hline \multicolumn{4}{|l|}{$\begin{array}{l}\text { SF-36 PCS score change from baseline at } \\
\text { week } 12\end{array}$} \\
\hline $\mathrm{N}$ & 185 & 201 & 206 \\
\hline LS mean $(95 \% \mathrm{Cl})$ & $1.6(0.6$ to 2.7$)$ & $5.2(4.1$ to 6.2$)$ & 7.1 (6.1 to 8.1$)$ \\
\hline LS mean difference $(95 \% \mathrm{Cl})$ & & $3.5(2.1$ to 5.0$)$ & $5.4(4.0$ to 6.9$)$ \\
\hline$P$ value & & $<0.001$ & $<0.001$ \\
\hline \multicolumn{4}{|c|}{$\begin{array}{l}\text { Proportion of patients achieving sIGA of psoriasis score of } 0 \text { or } 1 \text { and at least a 2-point improvement from } \\
\text { baseline at week } 16 \text { (for patients with baseline sIGA } \geq 2 \text { ) }\end{array}$} \\
\hline $\mathrm{N}$ & 163 & 171 & 164 \\
\hline$n(\%)$ & $15(9.2)$ & $63(36.8)$ & $66(40.2)$ \\
\hline Response rate mean difference $(95 \% \mathrm{Cl})$ & & $\begin{array}{l}27.6(19.2 \text { to } \\
36.1)\end{array}$ & $\begin{array}{l}31.0(22.3 \text { to } \\
39.8)\end{array}$ \\
\hline$P$ value & & $<0.001$ & $<0.001$ \\
\hline
\end{tabular}

PASI75 response at week 16 (for patients

with $\geq 3 \%$ BSA-psoriasis at baseline)

\begin{tabular}{|c|c|c|c|}
\hline $\mathrm{N}$ & 131 & 130 & 131 \\
\hline$n(\%)$ & $21(16.0)$ & $68(52.3)$ & $74(56.5)$ \\
\hline Response rate mean difference $(95 \% \mathrm{Cl})$ & & $\begin{array}{l}36.3(25.6 \text { to } \\
46.9)\end{array}$ & $\begin{array}{l}40.5 \text { (29.9 to } \\
51.0)\end{array}$ \\
\hline$P$ value & & $<0.001$ & $<0.001$ \\
\hline \multicolumn{4}{|l|}{$\begin{array}{l}\text { Self-Assessment of Psoriasis Symptoms score } \\
\text { change from baseline at week } 16\end{array}$} \\
\hline $\mathrm{N}$ & 182 & 191 & 200 \\
\hline LS mean $(95 \% \mathrm{Cl})$ & $-1.5(-4.7$ to 1.8$)$ & $\begin{array}{l}-24.4(-27.5 \text { to } \\
-21.2)\end{array}$ & $\begin{array}{l}-29.7(-32.8 \text { to } \\
-26.6)\end{array}$ \\
\hline LS mean difference $(95 \% \mathrm{Cl})$ & & $\begin{array}{l}-22.9(-27.4 \text { to } \\
-18.4)\end{array}$ & $\begin{array}{l}-28.2(-32.7 \text { to } \\
-23.8)\end{array}$ \\
\hline$P$ value & & $<0.001$ & $<0.001$ \\
\hline
\end{tabular}

Proportion of patients achieving minimal

disease activity at week 24

\begin{tabular}{|llll}
$\mathrm{N}$ & 212 & 211 & 218 \\
$\mathrm{n}(\%)$ & $6(2.8)$ & $53(25.1)$ & $63(28.9)$ \\
\hline Response rate mean difference $(95 \% \mathrm{Cl})$ & & $22.3(16.0$ to & $26.1(19.7$ to \\
& & $28.6)$ & $32.5)$ \\
\hline P value & & $<0.001$ & $<0.001$ \\
\hline
\end{tabular}

ACR20, 20\% improvement in American College of Rheumatolog criteria; BSA, body surface area; FACIT-F, Functional Assessment of Chronic Illness Therapy-Fatigue; HAQ-DI, Health Assessment Questionnaire-Disability Index; LS, least Assessment of Chronic lliness Therapy-Fatigue, HAQ-DD, Health Assessment Questionnaire-Disability Index; LS, least Form Health Survey Physical Component Summary score; sIGA, Static Investigator Global Assessment.

upadacitinib $15 \mathrm{mg}$ and three patients on upadacitinib $30 \mathrm{mg}$ ). Up to week 24, treatment-emergent opportunistic infections, excluding tuberculosis and herpes zoster, included one event each of candidiasis of the trachea and oropharyngeal candidiasis, both with upadacitinib $30 \mathrm{mg}$. Herpes zoster was reported in two, three and eight patients in the placebo, upadacitinib $15 \mathrm{mg}$ and $30 \mathrm{mg}$ arms, respectively; none of the cases were serious. One patient on upadacitinib $15 \mathrm{mg}$ and two patients on upadacitinib $30 \mathrm{mg}$ had cutaneous disseminated herpes zoster. No
Table 3 Additional secondary efficacy endpoints

\begin{tabular}{|c|c|c|c|}
\hline & Placebo & $\begin{array}{l}\text { Upadacitinib } 15 \\
\text { mg QD }\end{array}$ & $\begin{array}{l}\text { Upadacitinib } 30 \\
\text { mg QD }\end{array}$ \\
\hline \multicolumn{4}{|l|}{$\begin{array}{l}\text { ACR50 response rate at } \\
\text { week } 12\end{array}$} \\
\hline $\mathrm{N}$ & 212 & 211 & 218 \\
\hline$n(\%)$ & $10(4.7)$ & $67(31.8)$ & $82(37.6)$ \\
\hline $\begin{array}{l}\text { Response rate mean } \\
\text { difference }(95 \% \mathrm{Cl})\end{array}$ & & 27.0 (20.1 to 33.9$)$ & $32.9(25.9$ to 39.9$)$ \\
\hline Nominal $p$ value & & $<0.001$ & $<0.001$ \\
\hline \multicolumn{4}{|l|}{$\begin{array}{l}\text { ACR70 response rate at } \\
\text { week } 12\end{array}$} \\
\hline $\mathrm{N}$ & 212 & 211 & 218 \\
\hline $\mathrm{n}(\%)$ & $1(0.5)$ & $18(8.5)$ & $36(16.5)$ \\
\hline $\begin{array}{l}\text { Response rate mean } \\
\text { difference }(95 \% \mathrm{Cl})\end{array}$ & & 8.1 (4.2 to 11.9$)$ & $16.0(11.0$ to 21.1$)$ \\
\hline Nominal $p$ value & & $<0.001$ & $<0.001$ \\
\hline \multicolumn{4}{|l|}{$\begin{array}{l}\text { ACR20 response rate at } \\
\text { week } 2\end{array}$} \\
\hline $\mathrm{N}$ & 212 & 211 & 218 \\
\hline $\mathrm{n}(\%)$ & $23(10.8)$ & $69(32.7)$ & $73(33.5)$ \\
\hline $\begin{array}{l}\text { Response rate mean } \\
\text { difference }(95 \% \mathrm{Cl})\end{array}$ & & 21.9 (14.3 to 29.4$)$ & 22.6 (15.1 to 30.2$)$ \\
\hline Nominal $p$ value & & $<0.001$ & $<0.001$ \\
\hline \multicolumn{4}{|l|}{ Exploratory endpoints } \\
\hline \multicolumn{4}{|l|}{$\begin{array}{l}\text { Resolution of enthesitis } \\
\text { at week } 12 \text { (defined as } \\
\text { LEI=0) }\end{array}$} \\
\hline $\mathrm{N}$ & 144 & 133 & 152 \\
\hline$n(\%)$ & $29(20.1)$ & $52(39.1)$ & $73(48.0)$ \\
\hline $\begin{array}{l}\text { Response rate } \\
\text { difference }(95 \% \mathrm{Cl})\end{array}$ & & 19.0 (8.4 to 29.5$)$ & 27.9 (17.6 to 38.2$)$ \\
\hline Nominal $p$ value & & $<0.001$ & $<0.001$ \\
\hline \multicolumn{4}{|l|}{$\begin{array}{l}\text { Resolution of dactylitis } \\
\text { at week } 12 \text { (defined as } \\
\text { LDI=0) }\end{array}$} \\
\hline $\mathrm{N}$ & 64 & 55 & 50 \\
\hline$n(\%)$ & $23(35.9)$ & $35(63.6)$ & $38(76.0)$ \\
\hline $\begin{array}{l}\text { Response rate } \\
\text { difference }(95 \% \mathrm{Cl})\end{array}$ & & 27.7 (10.4 to 45.0$)$ & 40.1 (23.4 to 56.7$)$ \\
\hline Nominal p-value & & $<0.001$ & $<0.001$ \\
\hline
\end{tabular}

ACR20/50/70, 20\%/50\%/70\% improvement in American College of Rheumatology criteria; LDI, Leeds Dactylitis Index; LEI, Leeds Enthesitis Index; QD, once per day.

cases of herpes zoster with central nervous system involvement were observed. Hepatic disorders were reported in $3(1.4 \%)$ patients on placebo, $4(1.9 \%)$ on upadacitinib $15 \mathrm{mg}$ and 18 $(8.3 \%)$ on upadacitinib $30 \mathrm{mg}$; most were asymptomatic liver enzyme elevations.

Malignancies were reported in three patients in each upadacitinib arm (upadacitinib $15 \mathrm{mg}$ : one basal cell carcinoma, one prostate cancer, one rectal cancer; upadacitinib $30 \mathrm{mg}$ : one rectal adenocarcinoma, one ovarian and endometrial cancer, and one basal cell carcinoma) and none in the placebo arm. The time to event onset for these malignant events was $<6$ months.

There were no adjudicated gastrointestinal perforations reported through week 24 . One case of major adverse cardiovascular event (MACE; 0.5\%, non-fatal myocardial infarction) and one case of venous thromboembolic event (VTE; 0.5\%; pulmonary embolism) were reported in the upadacitinib $15 \mathrm{mg}$ arm; both patients had at least one risk factor (eg, obesity, hypertension or hypercholesterolaemia) for MACE or VTE, respectively. 
A.

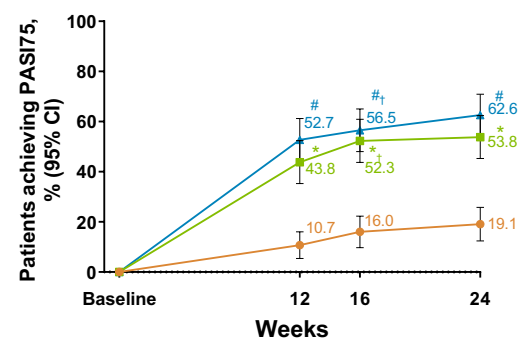

B.

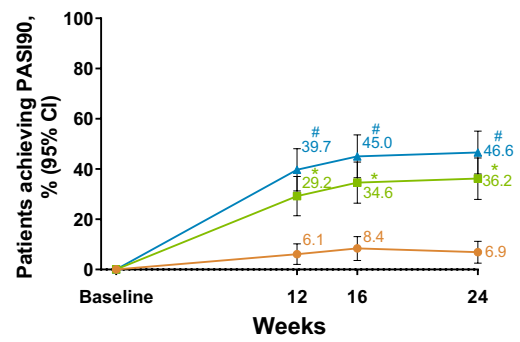

C.

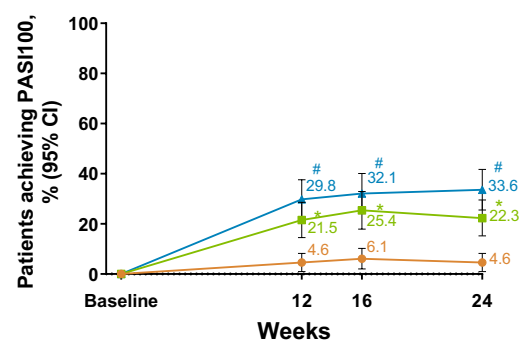

$\rightarrow$ Placebo $\rightarrow-$ Upadacitinib 15mg QD $\rightarrow$ Upadacitinib 30mg QD

Figure 2 Proportion of patients achieving (A) PASI75, (B) PASI90 and (C) PASI100. response over 24 weeks. * $\mathrm{p} \leq 0.05$; for upadacitinib 15 mg QD versus placebo; $\mathrm{\#} \leq 0.05$; for upadacitinib $30 \mathrm{mg}$ QD versus placebo; †significant in the multiplicity-controlled analysis. After week 16 , assessments have been performed. Patients may use concomitant treatments specifically for psoriasis per investigator judgement. Results are based on nonresponder imputation. 95\% Cls for response rate were calculated based on normal approximation to the binominal distribution. 95\% $\mathrm{Cls}$ for response rate difference were calculated based on normal approximation. Nominal p value was constructed using Cochran-Mantel-Haenszel test adjusted for the main stratification factor of current disease-modifying antirheumatic drug use (yes/no). PASI75/90/100, 75\%/90\%/100\% improvement in Psoriasis Area Severity Index; QD, once per day.

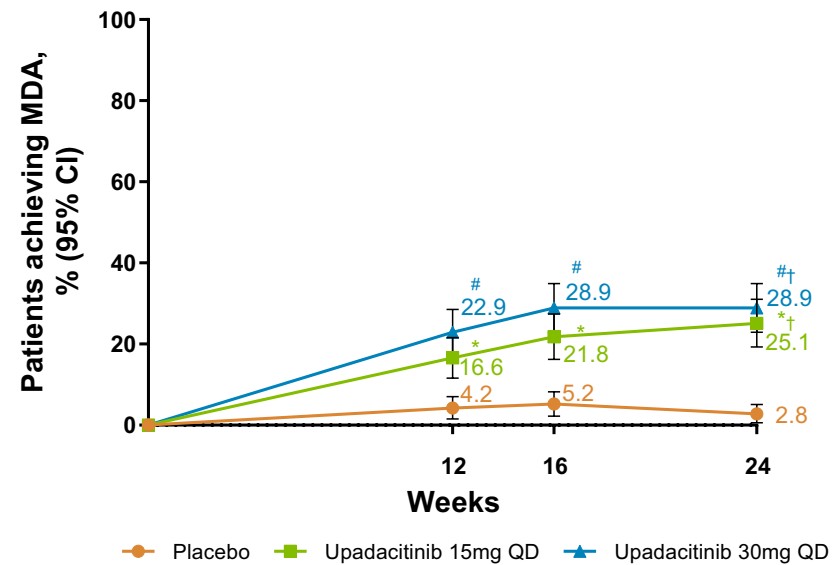

Figure 3 Proportion of patients achieving minimal disease activity (MDA) over 24 weeks. * $p \leq 0.05$; for upadacitinib $15 \mathrm{mg}$ QD versus placebo; \#p $\leq .05$; for upadacitinib $30 \mathrm{mg}$ QD versus placebo; tsignificant in the multiplicity-controlled analysis. Results for MDA at week 24 are based on non-responder imputation with additional rescue handling, where MDA at week 24 for patients rescued at week 16 is imputed as non-responder. $95 \% \mathrm{Cls}$ for response rate were calculated based on normal approximation to the binominal distribution. 95\% $\mathrm{Cls}$ for response rate difference were calculated based on normal approximation. Nominal p value was constructed using CochranMantel-Haenszel test adjusted for the main stratification factor of current disease-modifying antirheumatic drug use (yes/no). QD, once per day.

Over the 24-week period, one death was reported in the placebo arm related to a motor vehicle accident.

Generally, mean haemoglobin, neutrophil, lymphocyte and platelet levels remained within normal limits from baseline through week 24 in all treatment arms (online supplemental figure S12 and online supplemental table S5). There were two patients with grade 3 decreases in haemoglobin values in the upadacitinib $30 \mathrm{mg}$ arm (online supplemental table S4). Grade 3 decreases in neutrophils were reported in one patient on placebo

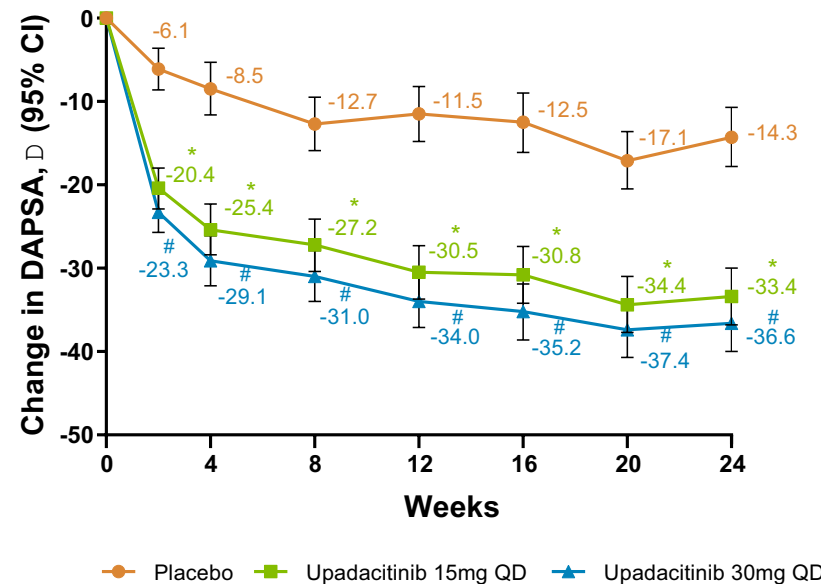

Figure 4 Change from baseline in Disease Activity in Psoriatic Arthritis (DAPSA) score. * $\mathrm{p} \leq 0.05$; for upadacitinib $15 \mathrm{mg}$ QD versus placebo; $\# p \leq 0.05$; for upadacitinib $30 \mathrm{mg}$ QD versus placebo. Within group least square mean and $95 \% \mathrm{Cl}$, and between group least square mean, $95 \%$ $\mathrm{Cl}$ and nominal $\mathrm{p}$ value are based on mixed-effect model repeated measurement (MMRM) analysis with unstructured variance-covariance matrix, including treatment, visit, treatment-by-visit interaction, the stratification factor current disease-modifying antirheumatic drug use (yes/no) as fixed factors and the continuous fixed covariate of baseline measurement. QD, once per day.

(0.5\%), two patients on upadacitinib $15 \mathrm{mg}$ (1.0\%) and four patients on upadacitinib $30 \mathrm{mg}(1.8 \%)$. No patients had grade 4 decreases in platelets, leucocytes, neutrophils or lymphocytes.

Isolated grade 3 increases in alanine aminotransferase or aspartate aminotransferase were observed in $\leq 1 \%$ of the patients among the treatment arms, and no grade 4 increases were observed (online supplemental table S4). No Hy's law cases were reported. Grade 3 increases in creatine phosphokinase (CPK) values were reported in one $(0.5 \%)$, one $(0.5 \%)$ and five $(2.3 \%)$ patients in the placebo, and upadacitinib $15 \mathrm{mg}$ and $30 \mathrm{mg}$ arms, respectively. Grade 4 increases in CPK values were reported in 
Table 4 Safety summary through week 24

\begin{tabular}{|c|c|c|c|}
\hline & $\begin{array}{l}\text { Placebo } \\
\mathrm{N}=212\end{array}$ & $\begin{array}{l}\text { Upadacitinib } 15 \mathrm{mg} \text { QD } \\
\mathrm{N}=211\end{array}$ & $\begin{array}{l}\text { Upadacitinib } 30 \mathrm{mg} \text { QD } \\
\mathrm{N}=218\end{array}$ \\
\hline \multicolumn{4}{|l|}{ Patients with adverse events (AE), $n(\%)$} \\
\hline Any AE & $139(65.6)$ & $135(64.0)$ & $170(78.0)$ \\
\hline Serious AE & $4(1.9)$ & $12(5.7)$ & $18(8.3)$ \\
\hline AE leading to discontinuation of trial drug & $11(5.2)$ & $15(7.1)$ & $20(9.2)$ \\
\hline Deaths & $1(0.5)$ & 0 & 0 \\
\hline Infection & $73(34.4)$ & $71(33.6)$ & $108(49.5)$ \\
\hline Serious infection & $1(0.5)$ & $1(0.5)$ & $6(2.8)$ \\
\hline Opportunistic infection excl. tuberculosis and herpes zoster & 0 & 0 & $2(0.9)$ \\
\hline Herpes zoster & $2(0.9)$ & $3(1.4)$ & $8(3.7)$ \\
\hline Active tuberculosis & 0 & 0 & 0 \\
\hline Hepatic disorder & $3(1.4)$ & $4(1.9)$ & $18(8.3)$ \\
\hline Malignancy & 0 & $3(1.4)$ & $3(1.4)$ \\
\hline Non-melanoma skin cancer & 0 & $1(0.5)$ & $1(0.5)$ \\
\hline Malignancy other than NMSC & 0 & $2(0.9)$ & $2(0.9)$ \\
\hline Lymphoma* & 0 & $1(0.5)$ & 0 \\
\hline Anaemia & $2(0.9)$ & $4(1.9)$ & $14(6.4)$ \\
\hline Neutropenia & $1(0.5)$ & $2(0.9)$ & $6(2.8)$ \\
\hline Lymphopenia & 0 & $2(0.9)$ & $2(0.9)$ \\
\hline Creatine phosphokinase elevation & $4(1.9)$ & $4(1.9)$ & $12(5.5)$ \\
\hline Renal dysfunction & $1(0.5)$ & 0 & $1(0.5)$ \\
\hline MACE (adjudicated) & 0 & $1(0.5)$ & 0 \\
\hline VTE (adjudicated) & 0 & $1(0.5)$ & 0 \\
\hline \multicolumn{4}{|l|}{ Laboratory data (LS mean change from baseline to week $24 \pm S D$ ) } \\
\hline Haemoglobin, g/L & $-0.7 \pm 7.44$ & $-3.6 \pm 9.45$ & $-5.5 \pm 10.78$ \\
\hline Neutrophils, $10^{9} / \mathrm{L}$ & $-0.056 \pm 1.6435$ & $-0.286 \pm 1.9578$ & $-0.610 \pm 2.0242$ \\
\hline Lymphocytes, $10^{9} / \mathrm{L}$ & $-0.076 \pm 0.5484$ & $-0.028 \pm 0.5460$ & $-0.057 \pm 0.5403$ \\
\hline Platelets, $10^{9} / \mathrm{L}$ & $1.7 \pm 59.35$ & $8.4 \pm 51.59$ & $18.3 \pm 72.08$ \\
\hline LDL-C, mmol/L & $0.003 \pm 0.6839$ & $0.219 \pm 0.6567$ & $0.453 \pm 0.9283$ \\
\hline $\mathrm{HDL}-\mathrm{C}, \mathrm{mmol} / \mathrm{L}$ & $-0.008 \pm 0.2278$ & $0.199 \pm 0.2599$ & $0.243 \pm 0.3451$ \\
\hline ALT, U/L & $-0.7 \pm 10.28$ & $6.8 \pm 16.05$ & $9.1 \pm 16.45$ \\
\hline AST, U/L & $-0.1 \pm 8.41$ & $6.5 \pm 22.17$ & $8.3 \pm 13.29$ \\
\hline Creatinine, umol/L & $2.2 \pm 10.87$ & $4.7 \pm 9.19$ & $5.3 \pm 9.48$ \\
\hline Creatine phosphokinase, U/L & $-19.9 \pm 140.87$ & $166.8 \pm 1198.70$ & $138.7 \pm 165.85$ \\
\hline
\end{tabular}

AEs were coded per the Medical Dictionary for Regulatory Activities. Laboratory data was graded using the Common Toxicity Criteria of the National Cancer Institute 4.03 .

*In the once per day upadacitinib $15 \mathrm{mg}$ arm, one event of treatment-emergent lymphocyte morphology abnormal was identified; per the investigator, no further diagnosis was made.

ALT, alanine aminotransferase; AST, aspartate aminotransferase; HDL-C, high-density lipoprotein cholesterol; LDL-C, low-density lipoprotein cholesterol; LS, least squares; MACE, major adverse cardiovascular events (defined as non-fatal myocardial infarction, non-fatal stroke and cardiovascular death); NMSC, non-melanoma skin cancer; QD, once per day; VTE, venous thromboembolic event (defined as deep vein thrombosis and pulmonary embolism).

two patients with placebo and one patient with upadacitinib 15 $\mathrm{mg}$. None led to discontinuation of trial drug, and there were no events of rhabdomyolysis. Slight mean elevations in low-density lipoprotein cholesterol (LDL-C) and high-density lipoprotein cholesterol (HDL-C) were observed in the upadacitinib arms versus the placebo arm (online supplemental figure S13). The ratios of LDL-C:HDL-C and total cholesterol:HDL-C generally remained constant through week 24 .

\section{DISCUSSION}

In this phase 3 trial of patients refractory or intolerant to biologic DMARDs, greater efficacy was demonstrated for upadacitinib 15 $\mathrm{mg}$ and $30 \mathrm{mg}$ once per day versus placebo for clinical manifestations of PsA including musculoskeletal symptoms (peripheral arthritis, enthesitis, dactylitis and spondylitis), psoriasis, physical function, pain, fatigue and quality of life.

Despite the advent of biologic DMARDs in PsA, many patients are either refractory or develop refractoriness to such treatment, underscoring the need for new therapy options. Both upadacitinib doses demonstrated efficacy in this particularly refractory population, wherein approximately $31 \%$ of the patients had failed $\geq 2$ biologic DMARDs. Furthermore, treatment with both upadacitinib doses resulted in improvements over placebo in more rigorous measures of disease control, as demonstrated by the ACR70, PASI100, sIGA 0/1, resolution of enthesitis and dactylitis, and MDA. Notably, efficacy was achieved with both upadacitinib doses as monotherapy and in combination with non-biologic DMARDs. Both upadacitinib doses also provided rapid efficacy on arthritis signs/symptoms, as evidenced by greater improvement of ACR20 compared with placebo at week 2.

Upadacitinib $30 \mathrm{mg}$ resulted in numerically greater efficacy when compared with $15 \mathrm{mg}$ for the primary and key secondary endpoints. Upadacitinib showed improvement in psoriasis similar to that observed in recent studies of biologics and small molecules in patients with PsA and previous inadequate response 
to biologic DMARDs. ${ }^{28-30}$ However, the efficacy differences in musculoskeletal manifestations between the upadacitinib doses appear to decrease by week 24 . Dose-dependent efficacy will be further evaluated with long-term data.

The safety profile of upadacitinib was generally consistent with results reported previously in rheumatoid arthritis trials. ${ }^{11-14}$ More serious infections, opportunistic infections and herpes zoster events were reported with upadacitinib $30 \mathrm{mg}$ compared with upadacitinib $15 \mathrm{mg}$ and placebo; however, percentages of malignancy and lymphopenia were the same in the upadacitinib arms. Although the sample size and trial duration may not be enough to make a determination from this study, there was a lack of MACE and VTE reports in the upadacitinib $30 \mathrm{mg}$ arm, suggesting no dose-dependent increased risk of these cardiovascular events with upadacitinib therapy. Few grade 3 or 4 laboratory abnormalities were seen in either upadacitinib arm.

Due to the 24-week duration of the placebo-controlled portion of this trial, limited safety conclusions may be made for events with longer latency or rare events. Long-term safety and efficacy of upadacitinib in patients with PsA are continuing to be evaluated in the ongoing extension phase. Further, this trial did not assess the effect of upadacitinib on radiographic progression compared with that of placebo. However, radiographic progression was evaluated in a parallel trial (NCT03104400) registered on clinicaltrials.gov.

In summary, in a PsA population refractory or intolerant to prior biologic DMARD therapy, upadacitinib $15 \mathrm{mg}$ and 30 mg once per day, with or without concomitant non-biologic DMARD therapy, showed rapid improvements versus placebo as measured by ACR20 response and efficacy across all clinical domains of PsA, including rigorous levels of efficacy in musculoskeletal and psoriatic skin disease measures as well as of comprehensive disease control. No new safety signals were identified compared with what has been observed with upadacitinib in rheumatoid arthritis.

\section{Author affiliations}

'Rheumatology, Swedish Medical Center, Seattle, Washington, USA

${ }^{2} \mathrm{~S}$ chool of Medicine, University of Washington, Seattle, Washington, USA

${ }^{3}$ AbbVie Inc, North Chicago, Illinois, USA

${ }^{4}$ Probity Medical Research and K Papp Clinical Research Inc, Waterloo, Ontario, Canada

${ }^{5}$ Department of Internal Medicine and Pediatrics, Ghent University, VIB Center for Inflammation Research, Ghent, Belgium, Gent, Belgium

${ }^{6}$ Department of Orthopaedics/Rheumatology, National Hospital Organization, Osaka Minami Medical Center, Kawachi-Nagano, Japan

${ }^{7}$ Medical Plus, Uherske Hradiste, Czech Republic

${ }^{8}$ Department of Pharmaceutics, University of Veterinary and Pharmaceutical Sciences Brno, Brno, Jihomoravský, Czech Republic

${ }^{9}$ Rheumatology Section, Pontifical Catholic University, School of Medicine, Porto Alegre, Brazil

${ }^{10}$ Department of Rheumatology, Royal National Hospital for Rheumatic Disease, Bath, UK

${ }^{11}$ Department of Pharmacy and Pharmacology, Centre for Therapeutic Innovation and Institute for Mathematical Innovation, University of Bath, Bath, UK

Acknowledgements AbbVie and the authors thank the patients who participated in the trial and all trial investigators for their contributions. The authors thank $\mathrm{Dr}$ Mark C Genovese for his support in the conduct of the trial. Ramona Vladea, PhD, of AbbVie provided medical writing support.

Collaborators JA, AP participated in the design of the study. PM, AL, JA, FB, ST, $E D, M K, W T$ participated in the acquisition and interpretation of data. AL, JA, RM, PZ, AP participated in the analysis and interpretation of data. SZ and XW participated in the analysis of data. AL, JA, and PM contributed to the drafting of the manuscript. All authors contributed to the critical revision of the manuscript for important intellectual content.AbbVie and the authors thank the patients who participated in the trial and all trial investigators for their contributions. The authors thank Dr. Mark C. Genovese for his support in the conduct of the trial. Ramona Vladea, PhD of AbbVie Inc. provided medical writing support.
Contributors JKA and ALP participated in the design of the study. PJM, AL, JKA, FEVdB, ST, ED, MK and WT participated in the acquisition and interpretation of data. $A L, J K A, R M M, P Z$ and ALP participated in the analysis and interpretation of data. SZ and XW participated in the analysis of data. AL, JKA and PJM contributed to the drafting of the manuscript. All authors contributed to the critical revision of the manuscript for important intellectual content.

Funding This study (NCT03104374) was funded by AbbVie, Inc.

Disclaimer AbbVie was the trial sponsor, and the trial was designed by AbbVie, the authors and investigators. Clinical data were collected by the investigators, their teams, and AbbVie. AbbVie was involved in data analysis, the interpretation of results and the preparation, review and approval of the final version of this report. All the authors had access to the data, reviewed and approved the final version, made the decision to submit the manuscript for publication, and attest to the accuracy and completeness of the data. The corresponding author had full access to all the data and the final responsibility to submit for publication. A medical writer, employed by AbbVie, assisted with preparing an initial draft under the direction of the authors.

Competing interests PJM has received research grants, consulting fees and/or speaker's fees from AbbVie, Amgen, Boehringer Ingelheim, Bristol Myers, Celgene, Eli Lilly, Galapagos, Genentech, Gilead, Janssen, Merck, Novartis, Pfizer, Sun Pharma and UCB. KP received honoraria or fees for advisory board, speaker and consultant services from AbbVie, Amgen, Astellas, Baxalta, Baxter, Boehringer Ingelheim, Bristol Myers Squibb, Celgene, Centocor, Dermira, Eli Lilly, Forward Pharma, Galderma, Genentech, GlaxoSmithKline, Janssen, Kyowa-Hakko Kirin, Leo Pharma, Medlmmune, Merck-Serono, Merck Sharp \& Dohme, Novartis, Pfizer, Regeneron, Roche, Sanofi-Genzyme, Stiefel, Sun Pharma, Takeda, UCB and Valeant and received research grants from AbbVie, Amgen, Astellas, Baxalta, Boehringer Ingelheim, Bristol Myers Squibb, Celgene, Centocor, Dermira, Eli Lilly, Galderma, Genentech, GlaxoSmithKline, Janssen, Kyowa-Hakko Kirin, Leo Pharma, Medlmmune, MerckSerono, Merck Sharp \& Dohme, Novartis, Pfizer, Regeneron, Roche, Sanofi-Genzyme, Stiefel, Takeda, UCB and Valeant. WT received grant/research support from AbbVie, Celgene and Eli Lilly and is a consultant for AbbVie, Celgene, Eli Lilly, Janssen, Novartis, and Pfizer, Speakers bureau: AbbVie, Amgen, Celgene, Eli Lilly, Janssen Novartis, UCB and Pfizer. FEVdB received speaker and/or consultancy fees from AbbVie, Celgene, Eli Lilly, Janssen, Merck, Novartis, Pfizer and UCB. ST received speaker fees from AbbVie, Asahi Kasei, Chugai, Daiichi Sankyo, Eli Lilly, Eisai, Mitsubishi Tanabe, Celgene and Novartis Pharma. ED received grant/research support from AbbVie, Eli Lilly, Glaxo Smith \& Kline, Novartis, Pfizer, UCB Biopharma SPRL, Sanofi - Aventis, Hexal AG, Gilead, R-Pharm, Janssen-Cilag, Galapagos NV. MK has participated in Advisory Boards and/or lectures for Pfizer, Abbott, Actelion, AstraZeneca, Amgen, Roche, Bristol Myers Squibb and Janssen and has received clinical trial honoraria from Pfizer, Amgen, AstraZeneca, Anthera Pharmaceuticals, Bristol Myers Squibb, Biogen Idec, Celltrion, Eli Lilly, Human Genome Sciences, Novartis, Roche, Sanofi, UCB Inc. AL, JKA, XW, SZ, PZ, ALP and RMM are AbbVie employees and may own AbbVie stock or options.

Patient and public involvement statement Patients and/or the public were not involved in the design, or conduct, or reporting, or dissemination plans of this research.

\section{Patient consent for publication Not required.}

Ethics approval The trial protocol was approved by independent ethics committees and institutional review boards.

Provenance and peer review Not commissioned; externally peer reviewed.

Data availability statement Data are available upon reasonable request. AbbVie is committed to responsible data sharing regarding the clinical trials we sponsor. This includes access to anonymised, individual and trial-level data (analysis data sets), as well as other information (eg, protocols and Clinical Trial Reports), as long as the trials are not part of an ongoing or planned regulatory submission. This includes requests for clinical trial data for unlicensed products and indications. This clinical trial data can be requested by any qualified researchers who engage in rigorous, independent scientific research, and will be provided following review and approval of a research proposal and Statistical Analysis Plan (SAP) and execution of a Data Sharing Agreement (DSA). Data requests can be submitted at any time and the data will be accessible for 12 months, with possible extensions considered. For more information on the process, or to submit a request, visit the following link: https:// www.abbvie.com/our-science/clinical-trials/clinical-trials-data-and-informationsharing/data-and-information-sharing-with-qualified-researchers.html.

Supplemental material This content has been supplied by the author(s). It has not been vetted by BMJ Publishing Group Limited (BMJ) and may not have been peer-reviewed. Any opinions or recommendations discussed are solely those of the author(s) and are not endorsed by BMJ. BMJ disclaims all liability and responsibility arising from any reliance placed on the content. Where the content includes any translated material, BMJ does not warrant the accuracy and reliability of the translations (including but not limited to local regulations, clinical guidelines, terminology, drug names and drug dosages), and is not responsible for any error and/or omissions arising from translation and adaptation or otherwise. 
Open access This is an open access article distributed in accordance with the Creative Commons Attribution Non Commercial (CC BY-NC 4.0) license, which permits others to distribute, remix, adapt, build upon this work non-commercially, and license their derivative works on different terms, provided the original work is properly cited, appropriate credit is given, any changes made indicated, and the use is non-commercial. See: http://creativecommons.org/licenses/by-nc/4.0/.

\section{ORCID iDs}

Philip J Mease http://orcid.org/0000-0002-6620-0457

Jaclyn K Anderson http://orcid.org/0000-0002-0893-3900

\section{REFERENCES}

1 Coates LC, Kavanaugh A, Mease PJ, et al. Group for research and assessment of psoriasis and psoriatic arthritis 2015 treatment recommendations for psoriatic arthritis. Arthritis Rheumatol 2016;68:1060-71.

2 Gossec L, Baraliakos X, Kerschbaumer A, et al. EULAR recommendations for the management of psoriatic arthritis with pharmacological therapies: 2019 update. Ann Rheum Dis 2020;79:700-12.

3 Singh JA, Guyatt G, Ogdie A, et al. Special article: 2018 American College of Rheumatology/National psoriasis Foundation guideline for the treatment of psoriatic arthritis. Arthritis Care Res 2019;71:2-29.

4 Mease PJ, van der Heijde D, Ritchlin CT, et al. Ixekizumab, an interleukin-17A specific monoclonal antibody, for the treatment of biologic-naive patients with active psoriatic arthritis: results from the 24-week randomised, double-blind, placebo-controlled and active (adalimumab)-controlled period of the phase III trial SPIRIT-P1. Ann Rheum Dis 2017;76:79-87.

5 Mease P, van der Heijde D, Landewé R, et al. Secukinumab improves active psoriatic arthritis symptoms and inhibits radiographic progression: primary results from the randomised, double-blind, phase III future 5 study. Ann Rheum Dis 2018;77:890-7.

6 Mease P, Hall S, FitzGerald 0, et al. Tofacitinib or adalimumab versus placebo for psoriatic arthritis. N Engl J Med 2017;377:1537-50.

7 Mease P, Coates LC, Helliwell PS, et al. Efficacy and safety of filgotinib, a selective Janus kinase 1 inhibitor, in patients with active psoriatic arthritis (EQUATOR): results from a randomised, placebo-controlled, phase 2 trial. Lancet 2018;392:2367-77.

8 Mclnnes IB, Kavanaugh A, Gottlieb AB, et al. Efficacy and safety of ustekinumab in patients with active psoriatic arthritis: 1 year results of the phase 3, multicentre, double-blind, placebo-controlled PSUMMIT 1 trial. Lancet 2013;382:780-9.

9 Deodhar A, Gottlieb AB, Boehncke W-H, et al. Efficacy and safety of guselkumab in patients with active psoriatic arthritis: a randomised, double-blind, placebo-controlled, phase 2 study. Lancet 2018;391:2213-24.

10 Parmentier JM, Voss J, Graff C, et al. In vitro and in vivo characterization of the JAK1 selectivity of upadacitinib (ABT-494). BMC Rheumatol 2018:2:23.

11 Burmester GR, Kremer JM, Van den Bosch F, et al. Safety and efficacy of upadacitinib in patients with rheumatoid arthritis and inadequate response to conventional synthetic disease-modifying anti-rheumatic drugs (SELECT-NEXT): a randomised, double-blind, placebo-controlled phase 3 trial. Lancet 2018;391:2503-12.

12 Fleischmann R, Pangan AL, Song I-H, et al. Upadacitinib versus placebo or adalimumab in patients with rheumatoid arthritis and an inadequate response to methotrexate: results of a phase III, double-blind, randomized controlled trial. Arthritis Rheumatol 2019;71:1788-800.
13 Genovese MC, Fleischmann R, Combe B, et al. Safety and efficacy of upadacitinib in patients with active rheumatoid arthritis refractory to biologic disease-modifying anti-rheumatic drugs (SELECT-BEYOND): a double-blind, randomised controlled phase 3 trial. Lancet 2018:391:2513-24.

14 Smolen JS, Pangan AL, Emery P, et al. Upadacitinib as monotherapy in patients with active rheumatoid arthritis and inadequate response to methotrexate (SELECTMONOTHERAPY): a randomised, placebo-controlled, double-blind phase 3 study. Lancet 2019:393:2303-11.

15 van Vollenhoven R, Takeuchi T, Pangan AL, et al. Efficacy and safety of Upadacitinib monotherapy in Methotrexate-naïve patients with moderately to severely active rheumatoid arthritis (SELECT-EARLY): a randomized, double-blind, Active-comparator, multi-center, Multi-country trial. Arthritis Rheumatol 2020. doi:10.1002/art.41384. [Epub ahead of print: 08 Jul 2020].

16 Taylor W, Gladman D, Helliwell P, et al. Classification criteria for psoriatic arthritis: development of new criteria from a large international study. Arthritis Rheum 2006;54:2665-73.

17 Fries JF, Spitz PW, Young DY. The dimensions of health outcomes: the health assessment questionnaire, disability and pain scales. J Rheumatol 1982;9:789-93.

18 Chandran V, Bhella S, Schentag C, et al. Functional assessment of chronic illness therapy-fatigue scale is valid in patients with psoriatic arthritis. Ann Rheum Dis 2007;66:936-9.

19 Ware J, Kosinski MA, Dewey JE. How to score version two of the SF-36 health survey. Lincoln, RI: Quality Metric, 2000.

20 Langley RGB, Feldman SR, Nyirady J, et al. The 5-point investigator's global assessment ( $\lg A)$ scale: a modified tool for evaluating plaque psoriasis severity in clinical trials. J Dermatolog Treat 2015;26:23-31.

21 Fredriksson T, Pettersson U. Severe psoriasis-oral therapy with a new retinoid. Dermatologica 1978;157:238-44.

22 Armstrong AW, Banderas B, Foley C, et al. Development and psychometric evaluation of the self-assessment of psoriasis symptoms (SAPS) - clinical trial and the SAPS - real world patient-reported outcomes. J Dermatolog Treat 2017;28:505-14.

23 Coates LC, Fransen J, Helliwell PS. Defining minimal disease activity in psoriatic arthritis: a proposed objective target for treatment. Ann Rheum Dis 2010;69:48-53.

24 Healy PJ, Helliwell PS. Measuring clinical enthesitis in psoriatic arthritis: assessment of existing measures and development of an instrument specific to psoriatic arthritis. Arthritis Rheum 2008:59:686-91.

25 Maksymowych WP, Mallon C, Morrow S, et al. Development and validation of the spondyloarthritis research Consortium of Canada (SPARCC) Enthesitis index. Ann Rheum Dis 2009;68:948-53.

26 Helliwell PS, Firth J, Ibrahim GH, et al. Development of an assessment tool for dactylitis in patients with psoriatic arthritis. J Rheumatol 2005;32:1745-50.

27 Schoels M. Psoriatic arthritis indices. Clin Exp Rheumatol 2014;32:109-12.

28 Gladman D, Rigby W, Azevedo VF, et al. Tofacitinib for psoriatic arthritis in patients with an inadequate response to TNF inhibitors. N Engl J Med 2017;377:1525-36.

29 Nash P, Kirkham B, Okada M, et al. Ixekizumab for the treatment of patients with active psoriatic arthritis and an inadequate response to tumour necrosis factor inhibitors: results from the 24-week randomised, double-blind, placebo-controlled period of the SPIRIT-P2 phase 3 trial. Lancet 2017;389:2317-27.

30 Mease PJ, Mclnnes IB, Kirkham B, et al. Secukinumab inhibition of interleukin-17A in patients with psoriatic arthritis. N Engl J Med 2015;373:1329-39. 